\title{
Green Synthesis of Copper Nanoparticles Extracted From Guar Seedling Under Cu Heavy-Metal Stress By Trichoderma Harzianum And Their Bio-Efficacy Evaluation Against Staphylococcus Aureus And Escherichia Coli
}

Farnaz Ahmadi-Nouraldinvand

University of Mohaghegh Ardabili

Mehdi Afrouz

University of Mohaghegh Ardabili

Sabry G Elias

Oregon Agricultural College: Oregon State University

Saeid Eslamian ( $\nabla$ eslamian747@gmail.com )

Isfahan University of Technology

\section{Research Article}

Keywords: Antioxidants, Cyamopsis tetragonoloba, Green Synthesis, Industrial Wastewater, Muncicipal Wastwater, Copper

Posted Date: July 30th, 2021

DOI: https://doi.org/10.21203/rs.3.rs-639339/v1

License: (c) (1) This work is licensed under a Creative Commons Attribution 4.0 International License. Read Full License

Version of Record: A version of this preprint was published at Environmental Earth Sciences on January 1st, 2022. See the published version at https://doi.org/10.1007/s12665-022-10184-4. 


\section{Abstract}

Copper nanoparticles were successfully synthesized with the help of the agriculturally beneficial fungus Trichoderma harzianum through a simple green and eco-friendly route. The objectives of this study were to: 1) evaluate the application of Trichoderma harzianum and assess the effect of guar plant cultivation on heavy metal contaminated lands of copper in municipal and industrial wastewaters, and 2) develop a method to increase the antibacterial effects on the risk of two bacteria (Staphylococcus aureus and Escherichia coli). Two factors were investigated: 1) two copper (Cu) levels, Natural Hoagland Arnold solution as a control, and application of $100 \mu$ lit $\mathrm{Cu}$ in Hoagland Arnold solution, and 2) two bio-fertilizer levels, no application as a control, and fungus application. Biosynthesized nanoparticles were characterized using transmission electron microscopy (TEM), scanning electron microscopy (SEM), X-Ray Diffraction (XRD) and Fourier transform infrared spectroscopy (FT-IR) analysis. Diffusion disk, minimum inhibitory concentration (MIC) and minimum bacterial concentration (MBC) were used for the antibacterial tests. The results of TEM and SEM showed that the copper nanoparticles synthesize from guar extract, had a spherical structure, and a size of approximately $20 \mathrm{~nm}$. The crystal structure from the XRD analysis, confirmed the synthesized particles as copper nanoparticles. The formation of Cu-NPs was confirmed by the FTIR analysis. Furthermore, the minimum inhibitory concentration (MIC) and minimum bactericidal concentration (MBC) of copper nanoparticles towards bacterial growth were evaluated. The copper nanoparticles and Trichoderma harzianum fungi presented antibacterial activity against Gram positive and Gram negative bacteria. The results suggested that green synthesis of nanoparticles using guar extracts can increase their antibacterial effect. The effect of copper nanoparticles and Trichoderma harzianum fungi on biochemical properties of guar was also investigated. The results showed that the highest antioxidant enzymatic activity and proline amino acid were obtained at $100 \mu$ lit $\mathrm{Cu}$ and $\mathrm{T}$. harzianum fungi application. Moreover, the results suggested that the use of T. harzianum fungi can be useful in increasing the resistance to heavy metal stress in plants by increasing the activity of some antioxidant enzymes and secondary metabolites.

\section{Introduction}

In recent decades, the production of nanoparticles and their application in the various aspects of plant sciences are increasing. So, the inimitable attributes of nanoparticles have given a progress to the great research activities directed towards nanoparticle preparation and applications. In fact, nanotechnology is a science that has the wide applications today in the pharmaceuticals environmental pollutions control (Ghaedi et al., 2015), the biomedical and pharmaceutical fields as alternative antimicrobial strategies due to the upsurge of infectious diseases and the appearance of antibiotic-resistant strains (Makarov et al., 2014). Biological approaches using microorganisms and plant extracts for metallic nanoparticle synthesis have been identified as viable alternatives to the other reported chemical methods (Bhavyasree \& Xavier, 2020). On the other hand, one of the production methods of nanoparticles is green synthesis and today, attention to this method for the production of nanoparticles is increasing (Mittal et al., 2013). One of the metals used in the metallic nanoparticles is copper, In fact, copper oxide nanoparticles have a 
special place. Furthermore, copper oxide nanoparticles have the antibacterial and antifungal properties (Bhavyasree \& Xavier, 2020).

However, the problem of soil health is critical for the suitable functioning of earthly ecosystems. As a result, even at low concentrations, it has an effect on element emissions, lowering soil productivity, ecosystem biota, fluxes of elements and water, human and animal health respectively (Farias et al., 2020). It is predicted that the sewage sludge will be used for the soil in the future. In this way, the valuable nutrients are returned to the soil, since the sewage sludge contains phosphorus, nitrogen, micronutrients such as copper, which can increase the crop yields and benefit the affected soil organisms. Hence, sewage sludge application to soil can create a risk of environmental contamination (Bogusz \& Oleszczuk, 2020). However, urban sewage harbours a wide range of the enteric pathogens like protozoa, viruses, bacteria, parasitic worms and eggs, and its uses calls for careful management of its associated health risks. Bacteria such as Staphylococcus aureus and Escherichia coli, on the other hand, have been found in wastewater that used to irrigate the farmlands. Copper is an essential element for humans and plants when present in shortage amount, while in excess it exerts the detrimental effects (Kumar et al., 2021). Of course, it is worth mentioning that among heavy metals, copper (cu) is mainly found in urban sewage sludge (Reis et al., 2020). In this way, phytoremediation is a natural-based solution relying on the natural capability of plants to recover soil, sediment, water surface and groundwater contaminated with toxic metals, organic pollutants and radionuclides. In fact, plants can be used for the pollutant stabilization, extraction, degradation, or volatilization (Manjate et al., 2020).

The use of Trichoderma harzianum is one of the available methods for reducing the harmful effects of heavy metals on plants. In fact, $T$. harzianum fungi can tolerate a broad range of environmental stresses such as heavy metals. Even in the presence of extreme $\mathrm{pH}$, temperature, or nutrient deficiency, the fungus can uptake a variety of heavy metals such as $\mathrm{Cu}, \mathrm{Cd}, \mathrm{Ag}$, and others from the soil and/or water. Some species of this fungus have the ability to clean the contaminated environment (Govarthanan et al., 2018). Trichoderma has been reported to increase the plant tolerance to heavy metal stress (Téllez Vargas et al., 2017). In addition, the use of Trichoderma fungi has been reported to significantly promote plant growth and alleviate the oxidative stress induced by the interactions of heavy metals (Li et al., 2019).

One of the main characteristics of legumes as a resource for phytoremediation is their role in providing additional Nitrogen compounds to the soil, thus improving soil fertility and ability to support biological growth. Hence, in this study, guar is used as a legume for phytoremediation (Amin et al., 2018). Guar or cluster bean (Cyamopsis tetragonoloba L.) is a drought-resistant annual leguminous crop that is predominantly grown in India and Pakistan (Mahla et al., 2020). Guar is one of the unique beans with a large spherical endosperm that contains a significant amount of galactomannans, which are used in a variety of food and industrial uses. In fact, guar seed compound of three parts consists of $14-17 \%$ hull, 35-42\% endosperm and 43-47\% germ (Sabahelkheir Murwan et al., 2015).

In general, irrigation with urban sewage because of the presence of the heavy metals such as copper microbiome of Escherichia coli and Staphylococcus aureus causes plant destruction. Thus, in the present 
study, Trichoderma harzianum was selected with the aim of evaluating their possible application in the phytoremediation of copper contaminated soil. Therefore, due to the rapid growth of guar, high tolerance to stress conditions and repairing potential to heavy elements, guar can be used to clean the soils contaminated with heavy metals. Thus, the main objective of the present research is to examine the green synthesis of copper nanoparticles extracted from guar by Trichoderma harzianum to clean municipal sewage. On the other hand, because of the plant's growth conditions, which were soilless and hydroponic, it would need to be cultivated in soil conditions in future experiments. Also, the use of several pH levels for a more appropriate evaluation is one of the study's limitations.

\section{Materials And Methods}

All of the chemicals used in this experiment were analytical grade and were used exactly as they were purchased. Hydrogen peroxide, Tris-chloride, Pyrogallol, Sulfosalicylic acid, Ninhydrin acid, Acetic acid, Phosphoric acid, sodium sulfate anhydrous, $\mathrm{CuSO}_{4}$ solution, Muller-Hinton Agar and Nutrient Broth (Merck, Germany) were used in this study. Also, the bacterial strains employed in this work were procured from Clinical Microbiology, Faculty of Medicine at Azad University, Ardabil, Iran. (Escherichia coli (ATCC 25922) and Staphylococcus aureus (ATCC 25923)).

In this study, two Gram-positive (Staphylococcus aureus) and Gram-negative (Escherichia coli) bacteria were used. The experimental factors were two copper nanoparticles levels (Natural Hoagland Arnold solution (control) and application $100 \mu$ lit $\mathrm{Cu}$ ) and two bio-fertilizer levels (no application (control) and fungi of application). That was examined in perlite-controlled culture medium and hydroponically at $\mathrm{pH}=$ 6 in three replications. The fungus used was Trichoderma harzianum, which was applied at the rate of 1 gr per $10 \mathrm{~kg}$ of perlite. First, the biochemical effects were evaluated. Then, the leaf tissue of each sample of copper nanoparticles was taken from the aqueous extract by the green synthesis method for tests (FTIR, XRD, TEM and SEM). Also, from four types of treatments, antibacterial tests of disk diffusion (essential oil, aqueous extract and copper nanoparticles) were evaluated. Finally, MIC[1] and MBC[2] tests of copper nanoparticles extracted from four treatments were performed on two Gram-positive (Staphylococcus aureus) and Gram-negative (Escherichia coli) bacteria.

\section{2-1. Preparation of the aqueous guar extract}

About $10 \mathrm{gr}$ of guar dried leaves powder with $100 \mathrm{ml}$ of deionized water was placed on a shaker incubator for 48 hours. Then, it was centrifuged at $5000 \mathrm{rpm}$ for $10 \mathrm{~min}$. After $10 \mathrm{~min}$ of centrifugation, filtered with whatman No. 1 filter paper to eliminate the fibrous impurities and stored at $4^{\circ} \mathrm{C}$ for the further experiments.

\section{2-2. Extraction of essential oil}

Guar aerial parts after collection, cleaning and separation of impurities were crushed with an electric grinder and passed through a sieve. A Clevenger apparatus was used to extract $100 \mathrm{~g}$ of plant samples. Fresh distilled water was used as extraction solvent and the ratio of material to liquid was 1:10 After four 
hours, the essential oil was collected and dried by sodium sulfate anhydrous and then stored at $4^{\circ} \mathrm{C}$ until analysis (Bai et al., 2020).

\section{2-3. Preparation of copper nanoparticles}

For the preparation of copper nanoparticles (Cu-NPs), the first $75 \mathrm{ml}$ of the obtained aqueous guar extract was added to $100 \mathrm{ml}$ of $0.01 \mathrm{M} \mathrm{CuSO}_{4}$ solution. It was then stirred for another 10 minutes to ensure the complete mixing. Afterwards, it was kept at $60^{\circ} \mathrm{C}$ for one day. In the next step, the solution was centrifuged twice at $12000 \mathrm{rpm}$ for $20 \mathrm{~min}$ to get Cu-NPs. The nanoparticles have been prepared when the color of the solution changed from green to amber yellow. The synthesized nanoparticles were dried in the oven at $60^{\circ} \mathrm{C}$ for more analysis (Mahmoudvand et al., 2020).

\section{2-4. Antibacterial screening by using of disk diffusion method}

The disk diffusion method was used to evaluate the antibacterial activity and the inhibitory zone of the essential oil, aqueous extract and copper nanoparticles against the bacteria studied in the present study. $100 \mathrm{~mL}$ of fresh bacterial culture was gently spread on the agar surface. A $6 \mathrm{~mm}$ diameter filter paper disk, impregnated with a $20 \mathrm{~mL}$ dose of Cu-NPs with a concentration of $20 \mathrm{mg} / \mathrm{mL}$ was used for screening antibacterial activities against Escherichia coli and Staphylococcus aureus grown on culture plates. Culture plates were incubated at $37 \mathrm{C}$ for $24 \mathrm{~h}$. After incubation, the inhibition zone of bacterial growth was measured in $\mathrm{mm}$. Antimicrobial activity was determined by measuring the diameter of the inhibition zones around the discs against the tested bacteria. Each disc diffusion assay in this test was repeated in triplicate (Ghaedi et al., 2015).

\section{2-5. Minimum Inhibitory Concentration (MIC)}

The dilution method was used to determine the Minimum Inhibitory Concentration (MIC). Minimum inhibitory concentration (MIC) was assessed by dilution in a liquid medium. Accordingly, $20 \mathrm{ml}$ of the liquid LB medium was transferred to a $50 \mathrm{ml}$ Falcon under sterile conditions. Then $1 \mathrm{ml}$ of bacterial suspension (Standardized based on McFarland turbidity) was added to the culture medium. After complete mixing with LB culture medium, $100 \mu \mathrm{l}$ of bacterial suspension was added to each of the 96well plates different concentrations of extract $(2.5,5,10,20,40,80,100$, and $120 \mathrm{mg} / \mathrm{ml})$ and essential oil of guar $(2.5,5,10,20,40,80,100$, and $120 \mu \mathrm{l} / \mathrm{ml})$ and copper nanoparticles $(0.125,0.25,0.5,1$, and $2 \mu \mathrm{g} / \mathrm{ml}$ ) were added to a 96-well plate to evaluate their antibacterial properties. Then a 96-well plate containing Escherichia coli and Staphylococcus aureus bacteria were transferred to a $37^{\circ} \mathrm{C}$ incubator and incubated for $24 \mathrm{~h}$. The lowest concentration in which no bacterial growth was observed was determined as the MIC.

\section{2-6. Minimum bactericidal concentration (MBC)}

To determine Minimum Bacterial Concentration $(\mathrm{MBC})$, an ounce was taken from the MIC and spread over a solid LB medium. After $24 \mathrm{~h}$ incubation at $37^{\circ} \mathrm{C}$, the minimum concentration with no bacterial 
growth was considered MBC. All tests were done in triplets. The results are presented as the average of these three replications.

\section{2-7. Investigation of properties of metal nanoparticles}

To evaluate the morphological properties of the obtained nanoparticles, TEM and SEM devices were used. However, the degree of crystallization was assessed using an XRD device. On the other hand, the percentage of compounds and functional groups of nanoparticles were evaluated by FTIR (Paulkumar et al., 2014).

\section{2-8. Biochemical parameters measurements}

Proline content in leaves was measured by the method of (Bates et al., 1973). Its absorbance was recorded at wavelength $520 \mathrm{~nm}$ using a spectrophotometer. The activity of catalase, peroxidase and polyphenol oxidase enzymes in flag leaves was determined by Kar and Mishra (1976) method and by spectrophotometer which were described as OD $\mu \mathrm{g}$ Protein $\mathrm{min}^{-1}$.

\section{2-9. Statistical analysis}

All tests were performed in 3 replications and the mean comparison was based on the LSD test at $5 \%$ probability level. The statistical analysis was carried out using SAS 9.4 and Excel application software.

[1]- Minimum Inhibitory Concentration

[2]- Minimum Bacterial Concentration

\section{Results And Discussions}

3 - 1. The effect of copper $(\mathrm{Cu})$ and Trichoderma harzianum fungi application on biochemical parameters of guar

Based on variance analysis, interaction effects of copper $(\mathrm{Cu})$ and Trichoderma harzianum fungi were significant in enzymatic antioxidants activities (Table 1). As shown in the mean comparison table, the highest enzymatic antioxidants activities were obtained when $100 \mu$ lit $\mathrm{Cu}$ and $T$. harzianum fungi were use. As, non-inoculation with T. harzianum and non-application of Cu-NPs decreased the catalase (63.59\%), peroxidase (44.02\%) and poly phenol oxidase (46.83\%) compared to inoculation with $T$. harzianum and $\mathrm{Cu}$ application (Table 2). In fact, it can be said that copper as abiotic stress can produce more ROS in the cell and cause secondary oxidative stress to plants. On the other hand, in this paper, it is demonstrated that enzymatic antioxidant activities such as catalase, peroxidase and poly phenol oxidase were implicated in the tolerance of Trichoderma harzianum to oxidative the stress caused by exposure to Cu. So, previous studies have reported that Trichoderma inoculation and copper application have the greatest effect on enzymatic antioxidants activities (Ernesto Juniors et al., 2020). 
On the other hand, the results analysis of variance showed that main effect of copper and the interaction of copper (Cu) and Trichoderma harzianum fungi significantly affected proline (Table 1). As can be seen in Table 2, the highest content of proline was $9.35 \mu \mathrm{g} / \mathrm{g} \cdot \mathrm{Fw}^{-1}$ that obtained from $100 \mu$ lit Cu application and inoculation with $T$. harzianum fungi and the lowest content of proline was in non-inoculation with $T$. harzianum fungi and no application of copper $\left(3.08 \mu \mathrm{g} / \mathrm{g} . \mathrm{Fw}^{-1}\right)$. In fact, the absence of fungi and copper reduced the content of proline by approximately $67.05 \%$ when compared to the application of $100 \mu$ lit $\mathrm{Cu}$ and $T$. harzianum fungi. Of many plants, the use of organic solute such as proline, mineral ions, particularly $\mathrm{Ca}$ and $\mathrm{K}$, for osmotic regulation. In fact, when cells are under stress, increased proline content protects cell membranes, proteins, cytoplasmic enzymes, and reactive oxygen species, as well as scavenges free radicals. Plants, in fact, can withstand the stress by increasing proline, polyamine, and protein production (Hosseinzadeh et al., 2018).

Table 1

Analysis of variance of biochemical traits as affected by copper and Trichoderma harzianum

\begin{tabular}{|llllll|}
\hline S.o.V & df & \multicolumn{2}{l}{ Mean square } & \\
\cline { 3 - 7 } & & Catalase & Peroxidase & Poly phenol oxidase & Proline \\
\hline Replication & 2 & 28.16 & 1.602 & 0.0015 & 1.44 \\
\hline Copper (Cu) & 1 & $3909.53^{* *}$ & $658.97^{* *}$ & $485.19^{* *}$ & $67.60^{* *}$ \\
\hline Trichoderma harzianum (TH( & 1 & $298.55^{*}$ & $4.407^{\text {ns }}$ & $65.56^{*}$ & $0.688^{\text {ns }}$ \\
\hline Cu*TH & 1 & $420.48^{*}$ & $127.76^{* *}$ & $83.57^{*}$ & $6.95^{*}$ \\
\hline Error & 6 & 48.49 & 3.033 & 11.02 & 0.925 \\
\hline C.V (\%) & - & 15.00 & 4.53 & 12.25 & 16.08 \\
\hline ns, * and ** indicating non-significant and significant at 5 and 1 \% level, respectively & \\
\hline
\end{tabular}


Table 2

Means comparison of biochemical traits as affected by copper and Trichoderma harzianum

\begin{tabular}{|c|c|c|c|c|}
\hline \multirow[t]{2}{*}{ Treatments } & Catalase & Peroxidase & Poly phenol oxidase & \multirow{2}{*}{$\begin{array}{l}\text { Proline } \\
\left(\mu \mathrm{g} \mathrm{g} \mathrm{Fw}{ }^{-1}\right)\end{array}$} \\
\hline & \multicolumn{3}{|c|}{$\left(O D \mu g\right.$ Protein $\left.\min ^{-1}\right)$} & \\
\hline $\mathrm{Cu}_{0} \mathrm{TH}_{0}$ & 27.44 & 27.14 & 20.43 & 3.08 \\
\hline $\mathrm{Cu}_{0} \mathrm{TH}_{1}$ & 29.30 & 34.88 & 21.04 & 4.13 \\
\hline $\mathrm{Cu}_{1} \mathrm{TH}_{0}$ & 53.56 & 43.17 & 28.48 & 7.35 \\
\hline $\mathrm{Cu}_{1} \mathrm{TH}_{1}$ & 75.37 & 48.49 & 38.43 & 9.35 \\
\hline LSD & 14.95 & 5.77 & 6.90 & 1.71 \\
\hline \multicolumn{5}{|c|}{$\begin{array}{l}\mathrm{TH}_{0} \text { and } \mathrm{TH}_{1} \text { : Non-inoculated, Inoculated with Trichoderma harzianum, Inoculation with Trichoderm } \\
\text { harzianum }\end{array}$} \\
\hline \multicolumn{5}{|c|}{$\mathrm{Cu}_{0}$ and $\mathrm{Cu}_{1}: 0,100 \mu$ lit Copper } \\
\hline
\end{tabular}

\section{3-2. Scanning Electron Microscopy (SEM)}

The Scanning Electron Microscopy (SEM) pictures of the synthesized copper nanoparticles are showed in Fig. 1 ( $A$ and $B$ ). This shape is used to confirm the size of the nanoparticles. In fact, SEM provided further insight into the surface morphology of the Cu-NPs. The experimental results showed that the diameter of the prepared copper nanoparticle, according to the image of SEM at $300 \mathrm{~nm}$ magnification, was about $15-30 \mathrm{~nm}$ and the shape is found to be spherical as shown in the Figs. 1A and 1B. The above results are in agreement with the findings of Hassanien et al. (2018).

\section{3-3. Transmission Electron Microscopy (TEM)}

Through transmission electron microscopy (TEM), it was easy to observe the shape and particle size of Cu-NPs. Therefore, the TEM analysis was used to observe the size and shape of nanoparticles. The TEM image of the synthesized copper nanoparticles is showed in Fig. 2 ( $A$ and $B$ ). This figure shows the spherical-sized particles of Cu-NPs in nano-dimensions. In fact, the TEM image (Figs. 2A and 2B), also confirms the spherical shape of Cu-NPs which the average particles are in the size range of $10-30 \mathrm{~nm}$. The above results are in agreement with the findings of Ismail (2019).

\section{3-4. X-Ray Diffraction}

XRD analysis is a very useful tool for identifying the structure of metal nanoparticles. Therefore, the XRD analysis was used to evaluate the crystallinity of green synthesized Cu-NPs, type and crystal phase. The XRD pattern of Cu-NPs as shown in Fig. 3 that demonstrates the diffraction peaks of Cu-NPs exhibiting three peaks of $2 \theta$ at $43.6(111), 50.80$ (200) and $74.4(220)$. The peaks match with the literature values of metallic copper (File No. 04-0836) (Rajesh et al., 2018), which further proves the formation of crystals of 
the copper nanoparticles. In fact, it can be said that the material in question was the copper nanoparticles and the sharpness indicates the crystalline nature of the as-prepared Cu nanostructure. The peaks observed in the XRD spectrum of copper nanoparticles synthesized in this study are consistent with the above (Hasheminya et al., 2018). Moreover, the average crystallite size of copper nanoparticles was analyzed using Scherrer's formula.

(Eq. 1)

$$
D=\frac{K \lambda}{\beta \cos \theta}
$$

Where $k=0.94$, the Scherrer's constant, $D$ is the mean crystallite size, $\lambda$ is the wavelength of the copper target, $\beta$ is the full width half maximum value (FWHM) of the diffraction peaks and $\theta$ is the diffraction angle. Thus, XRD is commonly used to determine the chemical composition and crystal structure, type and crystal phase of a material. (Caroling et al., 2015).

\section{3-5. Evaluation of factor groups by FT-IR}

The FT-IR technique was used to confirm the synthesis of nanoparticles as well as to investigate the interactions between the different species and changes in chemical compositions of the mixtures during bio-synthesis. The FT-IR spectra of the synthesized Cu-NPs are shown in Fig. 4. As can be seen in the Figure, the peaks observed in the range of 3410 and 2920 are associated with the $\mathrm{O}-\mathrm{H}$ and $\mathrm{H}$-bonded functional groups in the copper nanoparticles, respectively. Also, the band at the 2848 was ascribed to C$\mathrm{H}$ stretching vibrations. Furthermore, the carbonyl group, $\mathrm{C}-\mathrm{OH}$ stretching vibrations, and $\mathrm{C}-\mathrm{O}$ stretching were represented by the peaks at $1620,1504,1224$, and 1320 , respectively. This result also confirms that water soluble compound such as saponins which are present in the aqueous extract of guar leaf that have the ability to perform the stabilization of copper nanoparticles. A similar observation has been reported by the several works (e.g. Gopalakrishnan \& Muniraj, 2019).

\section{3-6. Antibacterial properties of copper nanoparticles, aqueous extract and essential oil extracted from the guar plant}

The results of the MIC and MBC analysis of the effect of extracted nanoparticles, aqueous extract and essential oil (Control, application of $\mathrm{Cu}$, application of Trichoderma harzianum and combined application of T. harzianum and $\mathrm{Cu}$ ) on bacteria Escherichia coli and Staphylococcus aureus treated guar showed that, the essential oils treated with $T$. harzianum and copper at a concentration of $80 \mu \mathrm{l} / \mathrm{ml}$ inhibited the growth of Escherichia coli and Staphylococcus aureus. Also, the results of the MBC study showed that the concentration of $100 \mu \mathrm{l} / \mathrm{ml}$ in this treatment is effective in killing these two bacteria. E. coli and $S$. aureus bacteria were both inhibited by extracts treated with $T$. harzianum and copper at concentrations of 80 and $40 \mathrm{mg} / \mathrm{ml}$, respectively. The concentration of $100 \mathrm{mg} / \mathrm{ml}$ in this treatment is effective in killing these two bacteria. The other factors investigated in this study included the minimum inhibitory concentration (MIC) and minimum bacterial concentration (MBC) of copper nanoparticles extracted from guar. 
According to the findings of this study, the extracted copper nanoparticles of plant inhibited the growth of E. coli and $S$. aureus bacterial in all of the treatments. Also, according to MBC results, the copper nanoparticles at a concentration of $0.25 \mathrm{mg} / \mathrm{ml}$ are able to kill this bacterium. Besides that, the extracted nanoparticles in the fourth treatment inhibit the growth of $S$. aureus bacteria at a concentration of 0.5 $\mathrm{mg} / \mathrm{ml}$, and a concentration of $0.25 \mathrm{mg} / \mathrm{ml}$ is sufficient to kill this bacterium. Generally, by comparing MIC and MBC obtained from nanoparticles, the aqueous extract and essential oils of the studied treatments it can be concluded that, the copper nanoparticles and aqueous extract of the fourth treatment (combined application of fungus and copper) have better antibacterial properties compared to the essential oils of this plant. So, the essential oil of this plant in concentrations of $120 \mu \mathrm{l} / \mathrm{ml}$ inhibited the growth of $E$. coli and $S$. aureus. Sources revealed that no research on the synthesis of copper nanoparticles with aqueous extract of guar plant has been published to date, and this is the first. However, the similar studies on other plants have been conducted (Amer \& Awwad, 2021; Dlamini et al., 2020; Hasheminya et al., 2018). The results of the minimum inhibitory concentration (MIC) and minimum bactericidal concentration (MBC) of Cu-NPs on the aforementioned bacteria are presented in Fig. 5 and Table 3.

Table 3

Antibacterial activity of copper nanoparticles, aqueous extract and essential oil extracted from the guar

\begin{tabular}{|c|c|c|c|c|c|c|}
\hline Bacteria & Extracted & Antibacteria & Control & $\mathrm{Cu}$ & $\mathrm{TH}$ & $\mathrm{TH} * \mathrm{Cu}$ \\
\hline \multirow[t]{6}{*}{ E.coli } & \multirow[t]{2}{*}{ Essential oil } & $\operatorname{MIC}(\mu \mathrm{l} / \mathrm{ml})$ & 120 & - & 120 & 80 \\
\hline & & $\operatorname{MBC}(\mu \mathrm{l} / \mathrm{ml})$ & - & - & - & 100 \\
\hline & \multirow[t]{2}{*}{ Aqueous extract } & $\mathrm{MIC}(\mathrm{mg} / \mathrm{ml})$ & 120 & 120 & 100 & 80 \\
\hline & & $\mathrm{MBC}(\mathrm{mg} / \mathrm{ml})$ & - & - & 120 & 100 \\
\hline & \multirow[t]{2}{*}{ Cu-NPs } & $\mathrm{MIC}(\mathrm{mg} / \mathrm{ml})$ & 2 & 1 & 1 & 0.5 \\
\hline & & $\mathrm{MBC}(\mathrm{mg} / \mathrm{ml})$ & 0.5 & 0.25 & 0.5 & 0.25 \\
\hline \multirow[t]{6}{*}{ S.aureus } & \multirow[t]{2}{*}{ Essential oil } & $\operatorname{MIC}(\mu \mathrm{l} / \mathrm{ml})$ & 100 & 120 & 100 & 80 \\
\hline & & $\operatorname{MBC}(\mu \mathrm{l} / \mathrm{ml})$ & - & - & 120 & 100 \\
\hline & \multirow[t]{2}{*}{ Aqueous extract } & $\mathrm{MIC}(\mathrm{mg} / \mathrm{ml})$ & 100 & 100 & 100 & 40 \\
\hline & & $\mathrm{MBC}(\mathrm{mg} / \mathrm{ml})$ & 120 & 120 & 120 & 100 \\
\hline & \multirow[t]{2}{*}{ Cu-NPs } & $\mathrm{MIC}(\mathrm{mg} / \mathrm{ml})$ & 1 & 1 & 1 & 0.5 \\
\hline & & $\mathrm{MBC}(\mathrm{mg} / \mathrm{ml})$ & 0.25 & 0.25 & 0.5 & 0.25 \\
\hline
\end{tabular}

\section{3-5. Evaluation of factor groups by FT-IR}

The results of studying the diameter and area of non-growth halo by image $\mathrm{j}$ software on the antibacterial properties of guar aqueous extract, essential oil and copper nanoparticles on Escherichia coli and 
Staphylococcus aureus by disk diffusion test showed that the nanoparticles extracted from the plant have the antibacterial properties on these two bacteria. In fact, by applying a concentration of $100 \mu \mathrm{l}$ of copper with Trichoderma harzianum, each of these three extracted compounds (extract, essential oil and nanoparticles) increased the diameter and area of non-growth halo in Escherichia coli and Staphylococcus aureus bacteria.

Copper nanoparticles extracted from guar in all of the four treatments showed the high antibacterial properties on E. coli and S. aureus. So that, in the concentration of $1 \mathrm{mg}$ of copper nanoparticles, the highest diameter and area of non-growth halo $(3.268 \mathrm{~mm})$ was observed in $S$. aureus bacteria and in the fourth treatment (combined application of fungus and copper). Furthermore, a $50 \mu \mathrm{l}$ aqueous extracts concentration significantly increased the diameter and area of the non-growth halo in $E$. coli bacteria. So that, the fourth treatment (combined application of fungus and copper) had the largest diameter and area of non-growth halo in $S$. aureus $(2.382 \mathrm{~mm})$, while the control treatment had the smallest diameter and area of non-growth halo $(0.931 \mathrm{~mm})$. In $S$. aureus bacteria, therefore, a concentration of $50 \mu \mathrm{l}$ of guar essential oil increased the diameter and area of non-growth halo. The results show that in comparison with the essential oil of this plant, the nanoparticles and aqueous extract from the fourth treatment (combined application of fungus and copper) had stronger antibacterial properties. In summary, most of the diameter and area of non-growth halo in the two studied bacteria in copper nanoparticles and aqueous extract was related to the fourth treatment. The above results are in agreement with the findings of Amer \& Awwad (2021).

\section{Conclusions}

Plants try to maintain the optimal conditions when they are stressed. As a result, many plant metabolites undergo the quantitative and qualitative changes in this regard. What was observed in this study also confirms this fact. The current study showed that the presence of Trichoderma harzianum fungi had a significant role in increasing antioxidant enzymes in guar under heavy metal stress conditions. This study also found that the copper nanoparticles, aqueous extract, and essential oils extracted from the fourth treatment plant increased the inhibition and killing of Escherichia coli and Staphylococcus aureus bacteria. Copper nanoparticles and aqueous extracts from the plant, in fact, had more inhibitory and lethal effects on Gram-positive and Gram-negative bacteria than the plant essential oil. However, because of the thicker walls, Gram-negative bacteria are more resistant than Gram-positive bacteria, according to the findings of this study. Therefore, in order to minimize the risks of irrigated products with municipal wastewater in agricultural lands, plants with high growth rates should be used. Hence, due to the rapid growth of guar, high tolerance to stress conditions and repair potential to heavy elements, guar can be used to clean the soils contaminated with heavy metals. Because of its high growth volume and antibacterial properties, using this plant as a cover plant is desirable. In general, the guar plant is considered to have a high economic and ecological value. As a result, this plant has the potential to clean heavy metal-contaminated areas while also producing valuable biomass that can generate income for landowners, that is considered the plant's economic value. In reality, the harvested biomass could be incinerated and disposed of, or the accumulated metal could be recovered and reused as biofuel. 


\section{Declarations}

\section{Acknowledgment}

The author would like to thank Professor Seyed Ataollah Siadat, of the Agricultural Sciences and Natural Resources University of Khuzestan and Professor Mohammad Taghi Alebrahim, of the University of Mohaghegh Ardabili for helpful advice on various technical issues examined in this paper.

\section{Financial \& competing interest's disclosure}

This study has been supported by the research grant of Tabriz University of Medical Sciences (Tabriz, Iran) and university of Mohaghegh Ardabili (Ardabili, Iran).

\section{References}

1. Amer, M. W., \& Awwad, A. M. (2021). Green synthesis of copper nanoparticles by Citrus limon fruits extract, characterization and antibacterial activity. 7(1), 1-8.

2. Amin, H., Arain, B. A., Jahangir, T. M., Abbasi, M. S., \& Amin, F. (2018). Accumulation and distribution of lead $(\mathrm{Pb}$ ) in plant tissues of guar (Cyamopsis tetragonoloba L.) and sesame ( Sesamum indicum L.): profitable phytoremediation with biofuel crops . Geology, Ecology, and Landscapes, 2(1), 51-60. https://doi.org/10.1080/24749508.2018.1452464

3. Bai, X., Aimila, A., Aidarhan, N., Duan, X., \& Maiwulanjiang, M. (2020). Chemical constituents and biological activities of essential oil from Mentha longifolia: effects of different extraction methods. International Journal of Food Properties, 23(1), 1951-1960. https://doi.org/10.1080/10942912.2020.1833035

4. Bates, L. S., Waldren, R. P., \& Teare, I. D. (1973). Rapid determination of free proline for water-stress studies. Plant and Soil, 39(1), 205-207.

5. Bhavyasree, P. G., \& Xavier, T. S. (2020). Green synthesis of Copper Oxide/Carbon nanocomposites using the leaf extract of Adhatoda vasica Nees, their characterization and antimicrobial activity. Heliyon, 6(2), e03323. https://doi.org/10.1016/j.heliyon.2020.e03323

6. Bogusz, A., \& Oleszczuk, P. (2020). Effect of biochar addition to sewage sludge on cadmium, copper and lead speciation in sewage sludge-amended soil. Chemosphere, 239, 124719. https://doi.org/10.1016/j.chemosphere.2019.124719

7. Caroling, G., Vinodhini, E., Mercy Ranjitham, A., \& Shanthi, P. (2015). Biosynthesis of copper nanoparticles using aqueous Phyllanthus embilica (Gooseberry) extract-characterisation and study of antimicrobial effects. Int. J. Nano. Chem. International Journal of Nanomaterials and Chemistry, 1(53), 53-63. http://dx.doi.org/10.12785/ijnc/010203

8. Dlamini, N. G., Basson, A. K., Simonis, J., Srirama, V., \& Pullabhotla, R. (2020). Biosynthesis of bioflocculant passivated copper nanoparticles, characterization and application. Physics and Chemistry of the Earth, 102898. https://doi.org/10.1016/j.pce.2020.102898 
9. Ernesto Juniors, P. T., Valeria, C. L., Santiago, P. O., Mario, R. M., \& Gabriela, S. J. (2020). Tolerance to oxidative stress caused by copper (Cu) in Trichoderma asperellum To. Biocatalysis and Agricultural Biotechnology, 29(August), 2-8. https://doi.org/10.1016/j.bcab.2020.101783

10. Farias, C. P., Alves, G. S., Oliveira, D. C., de Melo, E. I., \& Azevedo, L. C. B. (2020). A consortium of fungal isolates and biochar improved the phytoremediation potential of Jacaranda mimosifolia $D$. Don and reduced copper, manganese, and zinc leaching. Journal of Soils and Sediments, 20(1), 260271. https://doi.org/10.1007/s11368-019-02414-3

11. Ghaedi, M., Yousefinejad, M., Safarpoor, M., Khafri, H. Z., \& Purkait, M. K. (2015). Rosmarinus officinalis leaf extract mediated green synthesis of silver nanoparticles and investigation of its antimicrobial properties. Journal of Industrial and Engineering Chemistry, 31, 167-172. https://doi.org/10.1016/j.jiec.2015.06.020

12. Gopalakrishnan, V., \& Muniraj, S. (2019). Neem flower extract assisted green synthesis of copper nanoparticles - Optimisation, characterisation and anti-bacterial study. Materials Today: Proceedings, 36(xxxx), 832-836. https://doi.org/10.1016/j.matpr.2020.07.013

13. Govarthanan, M., Mythili, R., Selvankumar, T., Kamala-Kannan, S., \& Kim, H. (2018). Mycophytoremediation of arsenic- and lead-contaminated soils by Helianthus annuus and wood rot fungi, Trichoderma sp. isolated from decayed wood. Ecotoxicology and Environmental Safety, 151(November 2017), 279-284. https://doi.org/10.1016/j.ecoenv.2018.01.020

14. Hasheminya, S.-M., Rezaei Mokarram, R., Ghanbarzadeh, B., Hamishekar, H., \& Kafil, H. S. (2018). Physicochemical, mechanical, optical, microstructural and antimicrobial properties of novel kefirancarboxymethyl cellulose biocomposite films as influenced by copper oxide nanoparticles (CuONPs). Food Packaging and Shelf Life, 17, 196-204. https://doi.org/https://doi.org/10.1016/j.fpsl.2018.07.003

15. Hassanien, R., Husein, D. Z., \& Al-Hakkani, M. F. (2018). Biosynthesis of copper nanoparticles using aqueous Tilia extract: antimicrobial and anticancer activities. Heliyon, 4(12), e01077. https://doi.org/10.1016/j.heliyon.2018.e01077

16. Hosseinzadeh, S. R., Amiri, H., \& Ismaili, A. (2018). Evaluation of photosynthesis, physiological, and biochemical responses of chickpea (Cicer arietinum L. cv. Pirouz) under water deficit stress and use of vermicompost fertilizer. Journal of Integrative Agriculture, 17(11), 2426-2437.

17. Ismail, M. I. M. (2019). Green Synthesis and Characterizations of Copper Nanoparticles. Materials Chemistry and Physics. https://doi.org/10.1016/j.matchemphys.2019.122283

18. Kar, M., \& Mishra, D. (1976). Catalase, peroxidase, and polyphenoloxidase activities during rice leaf senescence. Plant Physiology, 57(2), 315-319.

19. Kumar, V., Pandita, S., Singh Sidhu, G. P., Sharma, A., Khanna, K., Kaur, P., Bali, A. S., \& Setia, R. (2021). Copper bioavailability, uptake, toxicity and tolerance in plants: A comprehensive review. Chemosphere, 262, 127810. https://doi.org/10.1016/j.chemosphere.2020.127810

20. Li, X., Zhang, X., Wang, X., Yang, X., \& Cui, Z. (2019). Bioaugmentation-assisted phytoremediation of lead and salinity co-contaminated soil by Suaeda salsa and Trichoderma asperellum. Chemosphere, 
224, 716-725. https://doi.org/10.1016/j.chemosphere.2019.02.184

21. Mahla, H. R., Sharma, R., Kumar, S., \& Gaikwad, K. (2020). Independent segregation of qualitative traits and estimation of genetic parameters and gene action for some quantitative traits in guar (Cyamopsis tetragonoloba L. Taub.). Indian Journal of Genetics and Plant Breeding, 80(2), 186-193. https://doi.org/10.31742/IJGPB.80.2.9

22. Mahmoudvand, H., Khaksarian, M., Ebrahimi, K., Shiravand, S., Jahanbakhsh, S., Niazi, M., \& Nadri, S. (2020). Antinociceptive effects of green synthesized copper nanoparticles alone or in combination with morphine. Annals of Medicine and Surgery, 51(August 2019), 31-36.

https://doi.org/10.1016/j.amsu.2019.12.006

23. Makarov, V. V, Love, A. J., Sinitsyna, O. V, Makarova, S. S., Yaminsky, I. V, Taliansky, M. E., \& Kalinina, N. O. (2014). "Green" nanotechnologies: synthesis of metal nanoparticles using plants. Acta Naturae (Англоязычная Версия), 6(1), 20..

24. Manjate, E., Ramos, S., \& Almeida, C. M. R. (2020). Potential interferences of microplastics in the phytoremediation of $\mathrm{Cd}$ and $\mathrm{Cu}$ by the salt marsh plant Phragmites australis. Journal of Environmental Chemical Engineering, 8(2), 103658. https://doi.org/10.1016/j.jece.2020.103658

25. Mittal, A. K., Chisti, Y., \& Banerjee, U. C. (2013). Synthesis of metallic nanoparticles using plant extracts. Biotechnology Advances, 31(2), 346-356.

https://doi.org/https://doi.org/10.1016/j.biotechadv.2013.01.003

26. Paulkumar, K., Gnanajobitha, G., Vanaja, M., Rajeshkumar, S., Malarkodi, C., Pandian, K., \& Annadurai, G. (2014). Piper nigrum Leaf and Stem Assisted Green Synthesis of Silver Nanoparticles and Evaluation of Its Antibacterial Activity Against Agricultural Plant Pathogens. The Scientific World Journal, 2014, 829894. https://doi.org/10.1155/2014/829894

27. Rajesh, K. M., Ajitha, B., Reddy, Y. A. K., Suneetha, Y., \& Reddy, P. S. (2018). Assisted green synthesis of copper nanoparticles using Syzygium aromaticum bud extract: Physical, optical and antimicrobial properties. Optik, 154, 593-600.

28. Reis, I. M. S., Alves, S. C. N., Melo, W. J. de, Silva, L. S., Freitas, L. de, Oliveira, I. A. de, Barros, I. B., Melo, G. M. P. de, \& Melo, V. P. de. (2020). Cadmium, copper, and chromium levels in maize plants and soil fertilized with sewage sludge. Australian Journal of Crop Science, 14(14(02):2020), 244-249. https://doi.org/10.21475/ajcs.20.14.02.p2006

29. Sabahelkheir Murwan, K., Abdalla Abdelwahab, H., \& Nouri Sulafa, H. (2015). Quality Assessment of Guar Gum (Endosperm ) of Guar ( Cyamopsis Quality Assessment of Guar Gum (Endosperm ) of Guar ( Cyamopsis tetragonoloba ). ISCA Journal of Biological Sciences ISCA J. Biological Sci, 1(December), 67-70. www.isca.in

30. Téllez Vargas, J., Rodríguez-Monroy, M., López Meyer, M., Montes-Belmont, R., \& Sepúlveda-Jiménez, G. (2017). Trichoderma asperellum ameliorates phytotoxic effects of copper in onion (Allium cepa L.). Environmental and Experimental Botany, 136, 85-93. https://doi.org/10.1016/j.envexpbot.2017.01.009. 
Figures

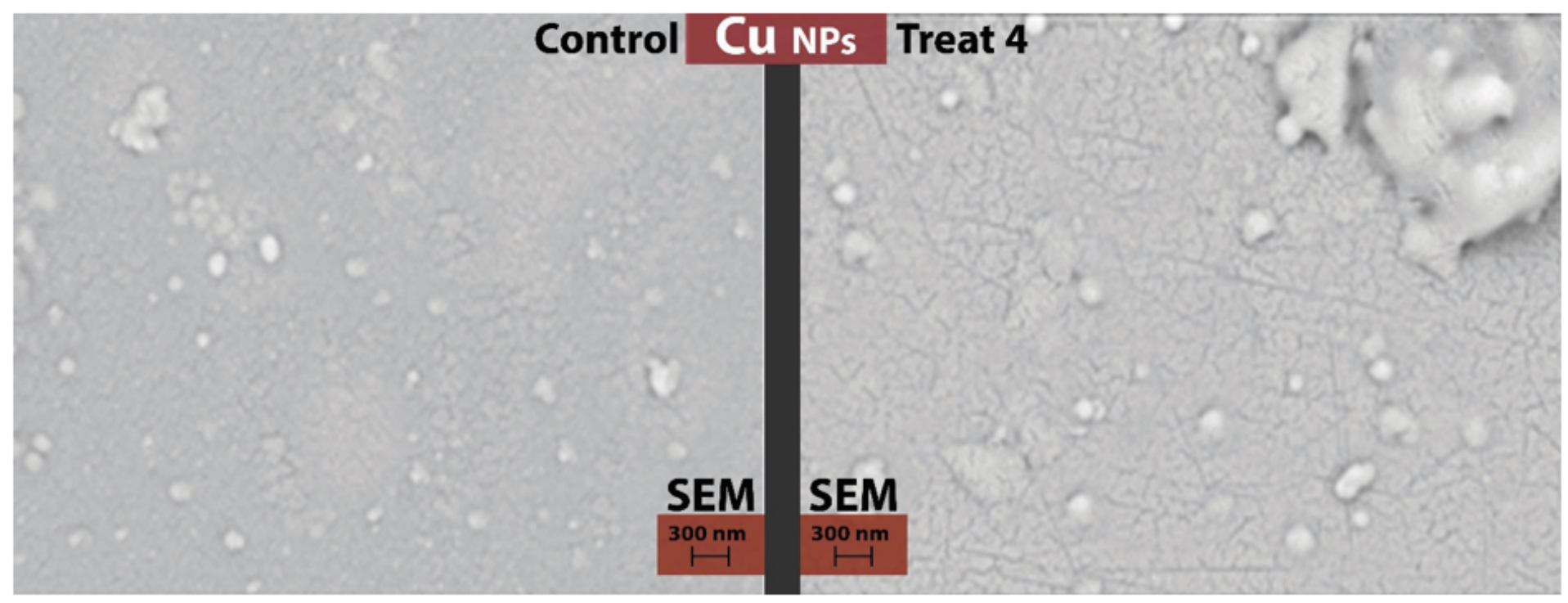

Figure 1

A, B, Selected SEM images of spherical shaped Cu-NPs.

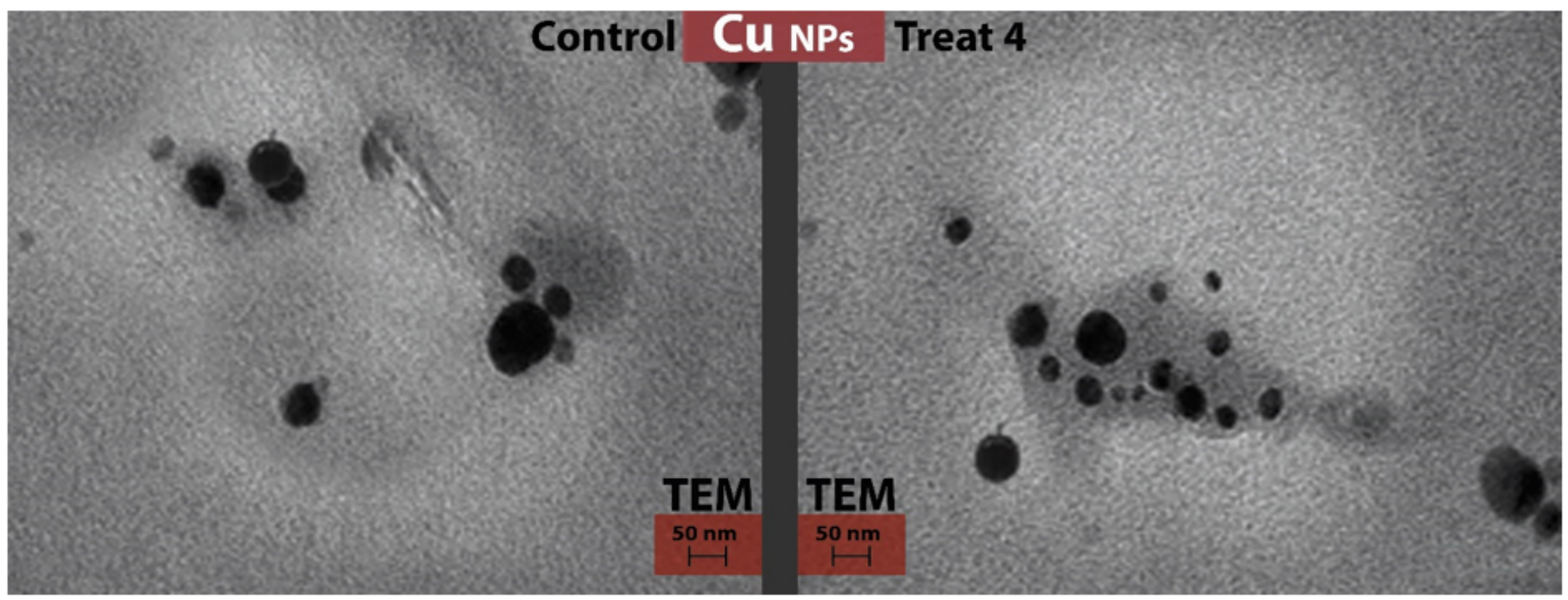

Figure 2

A, B, Selected TEM images of synthesized Cu-NPs. 


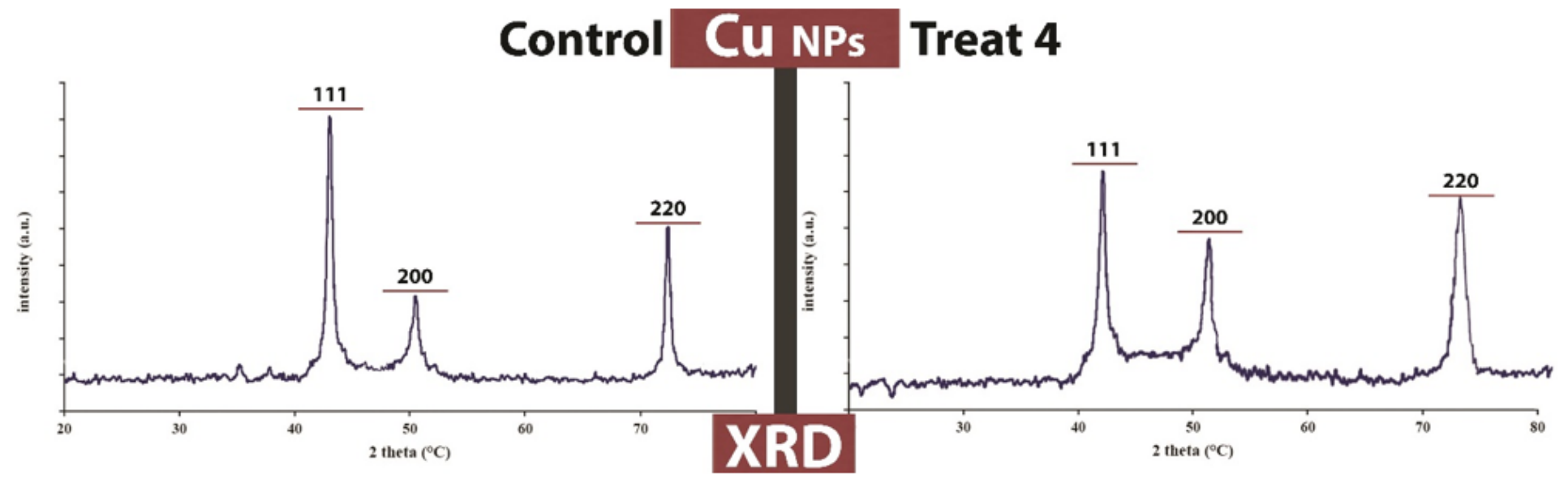

Figure 3

XRD pattern of copper nanoparticles (Cu-NPs)

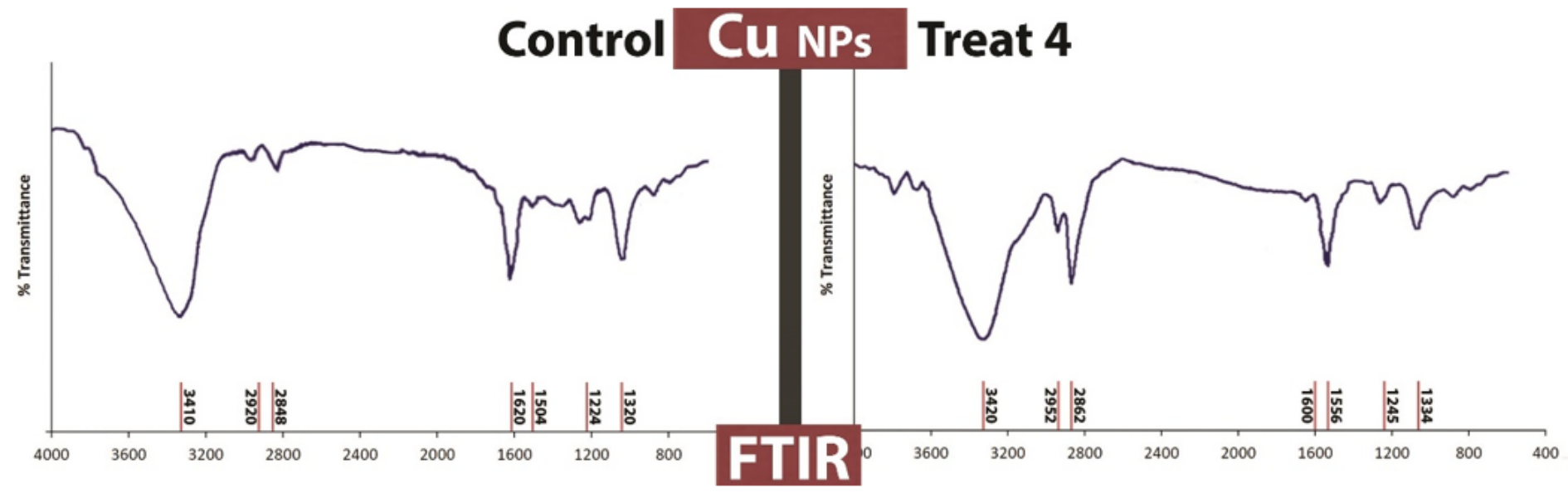

Figure 4

Fourier transform infrared spectroscopy (FTIR) of copper nanoparticles (Cu-NPs) 

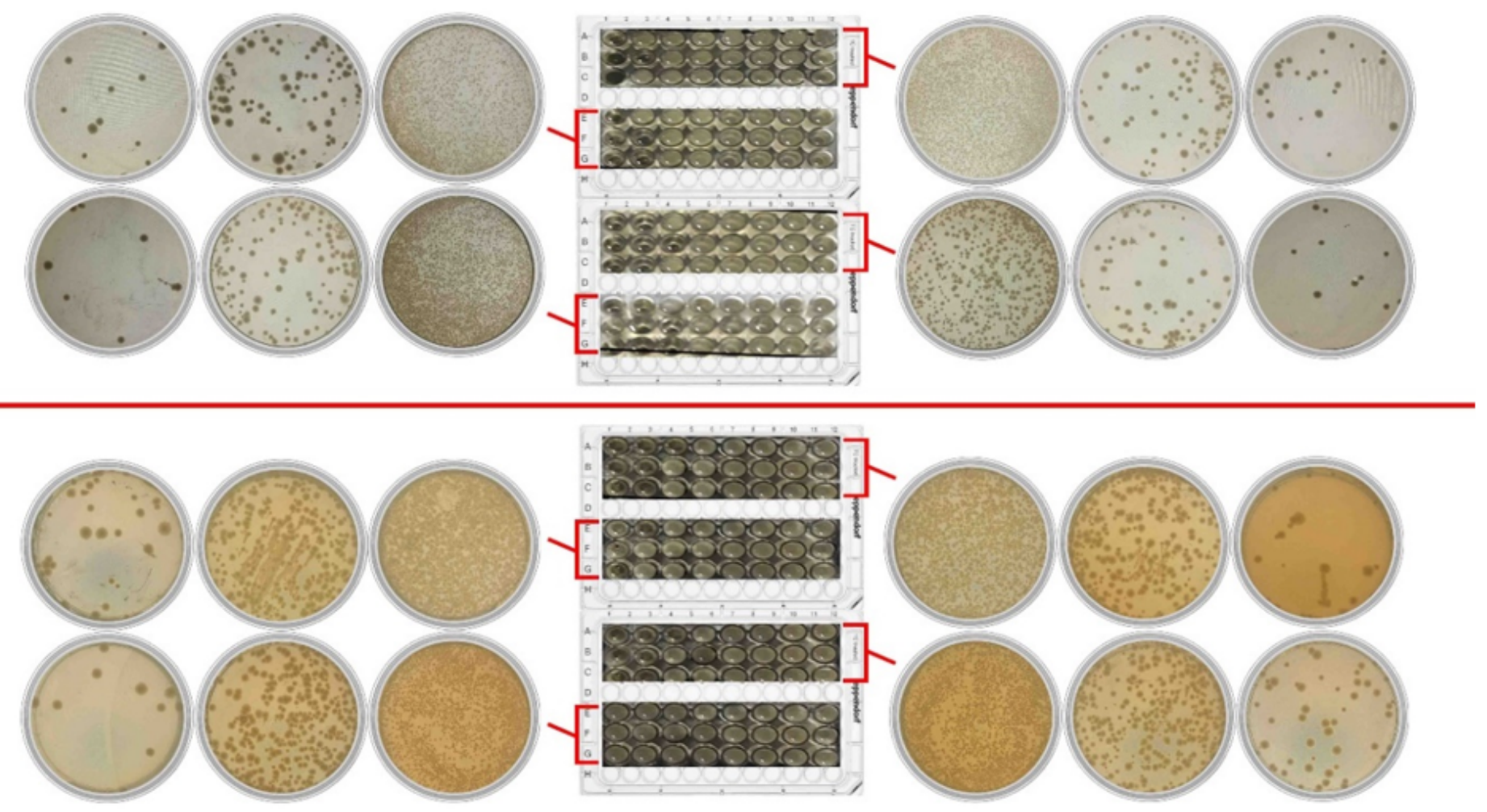

Figure 5

Image of microplates containing Escherichia coli (in the illustration above) and Staphylococcus aureus (in the illustration below) 24 hours after treatment with different concentrations of copper nanoparticles, aqueous extract and essential oil extracted from the guar 

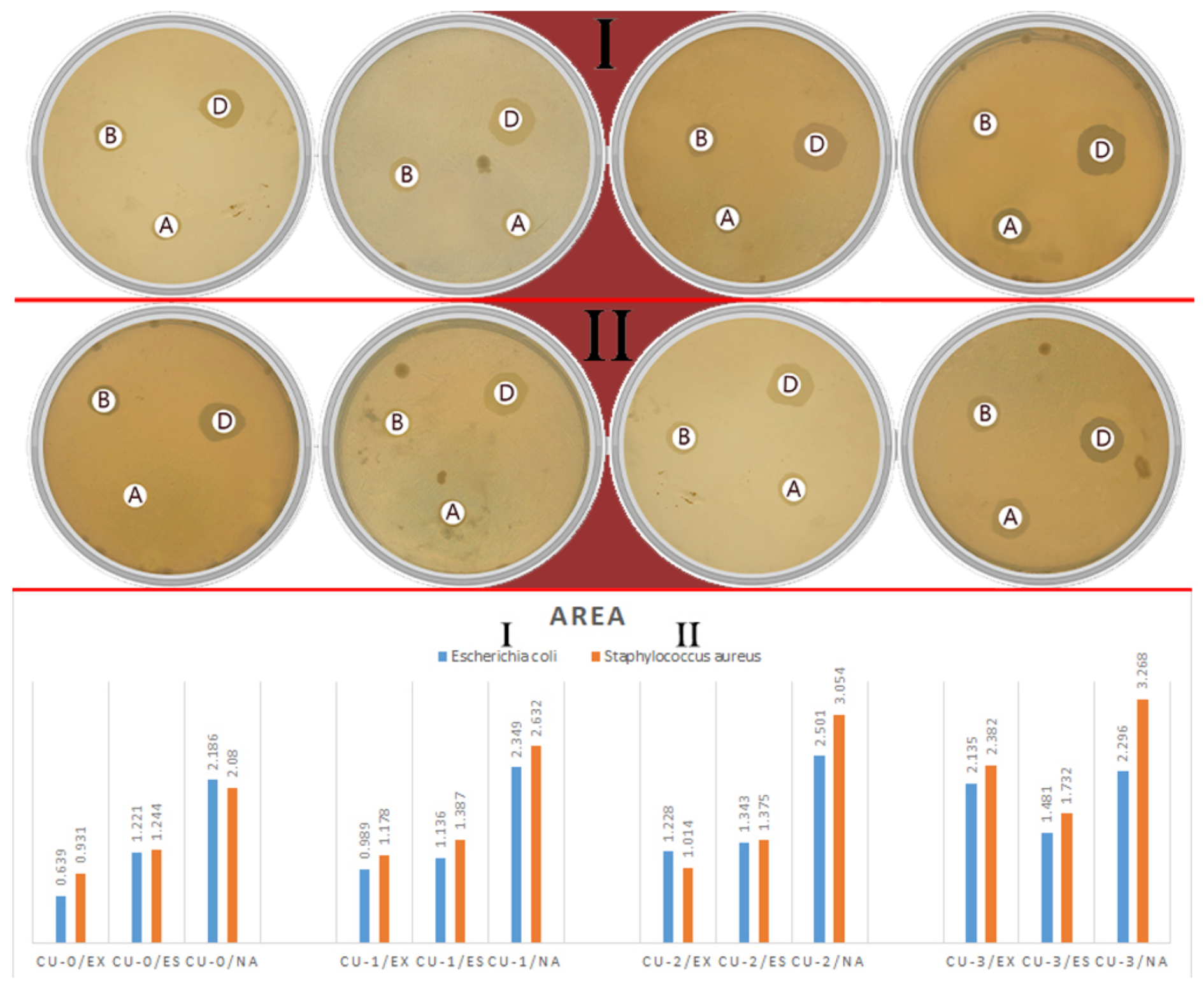

Figure 6

Growth halo area of aqueous extract, essential oil and copper nanoparticles extracted from guar using disk diffusion test

\section{Supplementary Files}

This is a list of supplementary files associated with this preprint. Click to download.

- Graphicalabstract.docx 